\title{
A USER-BASED METHOD TO TEST THE USABILITY OF UNIVERSITY OF ZAKHO WEBSITE
}

\author{
Nawzat S. Ahmed ${ }^{\text {a }}$ \\ ${ }^{a}$ Information Systems, Duhok Polytechnic University, Jurdistan Region, Iraq (nawzat.ahmed@dpu.edu.krd)
}

Received: Oct., 2019 / Accepted: Nov., 2019 / Published: Dec.,2019

https://doi.org/10.25271/sjuoz.2019.7.4.650

\begin{abstract}
:
Websites developed for an organisation, especially a university, always need maintenance and improvements to increase user satisfaction and to provide an environment that provides up-to-date information and services in efficient ways. Unfortunately, academic websites are often designed depended on the structure and objectives of an organisation, rather than on whether students, lecturers, and administrative staff find the website usable. This leaves the website users' needs and expectations unsatisfied. The University of Zakho (UoZ), a public university in the Kurdistan Regional Government, is developing its website to include most of the information required. However, the usability of this website still needs to be checked to know whether or not it satisfies users. This study employs a user-based method to get the rate of usability satisfaction from the perspective of students and academic staff, and it investigates whether the occupation has significant impacts on usability satisfaction. This method is achieved by using a Website Analysis and Measurement Inventory (WAMMI) questionnaire, which is including five factors: attractiveness, controllability, helpfulness, efficiency, and learnability. The study offers recommendations and suggestions to the UoZ web developers for improving the website during the maintenance period. Further, this study proposes ways to enhance the academic websites usability.
\end{abstract}

KEYWORDS: usability, educational websites, user-based method, user satisfaction, The University of Zakho.

\section{INTRODUCTION}

Nowadays, a website is a key factor in the success of an organisation in the global market. This comes from supporting most recent information and services to beneficiaries of such websites. Further, the website represents an organisation's mission, vision, and perspective. In the recent corporate environment, the website also deserves as a method of communication, whereby the organisation can communicate with its partners (Jabar, Usman, \& Awal, 2013). Universities are also using websites to provide services to its students, staff, and faculty. Three major functions of a university website has been identified by Harpel-Burk (2006), which are "promotion and marketing, online services, and providing a vehicle for individuals and groups to communicate'. The usability of an educational website also can improve the ranking of the university (Hasan, 2014).

The academic website promotes communication between academic and non-academic staff, students, alumni, and guests. Such websites are providing information about all activities of educational institutes. Moreover, these institutions require to use every advantage to promote positive activities for their various constituents. This can be done in order to pick full merit of the opportunities that the website provides (Caglar \& Mentes, 2012). Potential students can expect having full information when checking out a school's website. Based on the website usability, many website visitors will face the difficulty to find what they need. This is because these sites are established in different ways (Bautista, 2010).

The usability of any website has supposed a great deal of importance regarding the website usability by users (Patterson \& Alles, 2004). Also, Ahmad, Hussain, Flayyih, Abdulwahab, and Sabri (2017) argue that the website usability is a primary demand in order to survive in the internet community. So, website developer should focus on user's needs in order to provide a satisfy website. Web design must also make sure that users can complete tasks on the web successfully and without difficulty (Yan \& Guo, 2010).

To satisfying website users' needs, there are three methods for testing website usability. The first testing is a usability inspection method. This method of testing is used to identify usability problems of any website. Also, it improves the usability of interface design. One example is heuristic evaluation, which includes principles or guidelines of design based on a group of experts predicts. Second example is cognitive walkthrough testing. This testing fucoses on one evaluator or a group of them regarding the inspection of a user interface for any website usability testing. The second testing is a usability test-based method. In this second method of testing is suppling information requirements in terms of users' interaction and interface's needs for a specific website. The usability test-based method is using questionnaire, as a common tool, in order to extract, collect and record required information regarding the measurement of user satisfaction for website usability. The third testing is a tool-based automated evaluation method. This method is using an automated tool to identify internal website attributes regarding the programming used, the number of pages, the size of images, and etc. (AlRadaideh, Abu-Shanab, Hamam, \& Abu-Salem, 2011; Hasan, 2014; Jabar et al., 2013).

To measure academic website usability, many researchers have employed usability test-based methods using questionnaires. Such measurements can examine many factors, depending on the questionnaire used and the objective of the research (Hasan, 2014; Jabar et al., 2013; Mentes \& Turan, 2012; Mustafa \& AlZoua'bi, 2008; Thowfeek \& Salam, 2014). Therefore, This study employs a usability test based on a questionnaire, adopting the WAMMI questionnaire used by Caglar and Mentes (2012) and Jabar et al. (2013). This type of 
questionnaire measures attractiveness, controllability, helpfulness, efficiency, and learnability of any website as five factors to assess the website usability(Claridge \& Kirakowski, 2016).

\section{RELATED WORKS}

Many academic researches have done using the usability tools to evaluate websites. For example, Abdullah and Wei (2008) were selected four Malaysian online news websites, as a case study, in order to evaluate their website usability. These websites are 'The Star, The New Straits Times, Berita Harian, and Utusan Malaysia'. The researchers used a questionnaire consisting of 24 questions. Respondents were 80 online news readers as a non-probability sampling for the study. The results showed both positive and negative aspects of our selected websites regarding the "content, organisation and readability, navigation and links, user interface design, performance, and effectiveness". The results can be also used by designers and developers in order to improve the usability of websites. Based on the final results, in has been found that the New Straits Times website conducted the highest satisfaction rating from others. Caglar and Mentes (2012) tested the usability of the European University of Lefke (EUL) website regarding the student utilisation. WAMMI questionnaire was used in order to analyse EUL website usability. This questionnaire was distributed among 293 students, which are studying at different faculties. Fore the data examination, regression and nonparametric techniques were used. The study results were shown problems of the website usability and their discontent at EUL, which is in Northern Cyprus.

Regarding the very recent study on the academic website usability, Huang and Bilal (2019) examined the interactions of international $\mathrm{PhD}$ candidates regarding the recruitment web pages for the University of Tennessee's website, Knoxville (UTK). The study employed both quantitative and qualitative methods for data collection. The study results showed that the search process through browsing preferred by participants. This could be because of the search tasks they performed. Another study by Panagopoulos, Menychtas, Tsanakas, and Maglogiannis (2019) used a quantitative method to test the usability scale on 50 academic websites. That study focused on the satisfaction of users in using their academic websites. Melgarejo, Del Río, and Vilchez (2019) tested web usability in Peruvian Universities with users. These studies were done because most universities pay considerable attention on delivering important news or information through websites to their students, staff and guests in order to enhance the education process.

Mentes and Turan (2012) tested the usability of the academic website of Namık Kemal University (NKU). The study researchers provided guidelines to improve the usability of websites. Then, the research determined that six theoretical factors were positively affected the website usability. The research also showed that five of these factors affected the website usability perceptions of NKU members positively and significantly. The study also showed that perceptions of users, as demographic factors, have positive impacts on the usability regarding the gender and web experience. The researchers made recommendations for improving website usability.

Hasan (2012) attained criteria for testing the academic website usability using 25 design issues which are, ease of use and communications, design, organisation/architecture, navigation and content. These criteria were gained from the viewpoint of 237 students. These students were selected from the faculty of Administration and of Information Technology. The study showed that there were positive impacts on the website usability from the perspective of students regarding the aforementioned issues.
Most of the researchers have focused on improving the websites' usability by designing any website, especially academic websites, based on users' perceptions. Therefore, questionnaires have been and are still being used to test the usability of websites. These include: The National Institute of Standards and Technology Web Metrics (NIST Web Metrics), Software Usability Measurement Inventory (SUMI), Website Analysis and Measurement Inventory (WAMMI), Questionnaire for User Interface Satisfaction (Melgarejo et al.) and Measuring the Usability of Multi-Media (MUMMS) to assess multimedia software (Jabar et al., 2013). Another stander questionnaire called System Usability Scale (SUS) has been used as a tool to measure the usability level of any product or system (Kaya, Ozturk, \& Gumussoy, 2019). However, this tool is just to measure the effectiveness, efficiency and satisfaction of any system in the earlier stage during one month of the system implementation with at least 12 participants due to this tool is free and easy of use by including only 10 items (Ahmed, 2013; Haji \& Ahmed, 2017)

Based on that, many researchers have used WAMMI questionnaire to test the website usability from the perspective of hundreds of users. Such questionnaire has 20 standard statements and has been scientifically approved and has a reliability and data rating between 0.90 and 0.93 (Jabar et al., 2013).

The 20 WAMMI statements were attained from a huge number of questions based on users' experiences with websites. These statements were emerged after several testing and analysing processes. These statements also extract the predictive of user experience. Therefore, the assessment of any website usability, WAMMI proposes five factors (Claridge \& Kirakowski, 2016). Table 1 shows the explanation of these five factors briefly.

Table 1. WAMMI Factors

(http://www.wammi.com/demo/graph.html)

\begin{tabular}{|l|l|}
\hline Factors & Explanation \\
\hline Attractiveness & $\begin{array}{l}\text { An Attractive site is visually pleasing, and it } \\
\text { offers much of direct interest to the respondents, } \\
\text { whether it be functionality or information. } \\
\text { If a site scores well on Controllability, the } \\
\text { respondents most probably feel they can navigate } \\
\text { around it with ease and do the things they want to } \\
\text { do. Poor Controllability usually means a poorly } \\
\text { organised site that disrupts the way they } \\
\text { normally expect to do things. }\end{array}$ \\
$\begin{array}{l}\text { When respondents give a high Efficiency rating, } \\
\text { they feel they can quickly locate and do what } \\
\text { interests them in an effective and economical } \\
\text { manner. They feel that the website responds } \\
\text { (possibly, the pages load) at a reasonable speed. }\end{array}$ \\
$\begin{array}{l}\text { A site high on Helpfulness corresponds with the } \\
\text { respondents' expectations about its content and } \\
\text { structure. A site low on Helpfulness can be } \\
\text { misleading about its layout and content. } \\
\text { When Learnability is high, respondents feel they } \\
\text { can use the site with a minimum of introduction. } \\
\text { Everything is easy to understand from the start. } \\
\text { When Learnability is low, respondents feel that } \\
\text { the site may use concepts or terminology which } \\
\text { are unfamiliar. More explanations are needed. }\end{array}$ \\
\hline
\end{tabular}

In the previous studies, the researchers tested the usability of educational websites using quantitative methods and targeting user-based methods. The aim was to have a roadmap for designing a website based on users' requirements and reach a high usability score. Based on that, this research also employed a user-based method, using the five factors in WAMMI to measure the usability of the website of the University of Zakho, based on the viewpoints of students and staff.

\section{METHODOLOGY}

The evaluation of the University of Zakho website usability is the main target of this study. This section identifies the details 
of this study which are: a questionnaire-based evaluation method, the research model, research objectives, and sample selection. The following sub-sections clarify these details.

\subsection{Questionnaire-based evaluation method}

The questionnaire-based evaluation method included responding to WAMMI questionnaire in order to evaluate the University of Zakho website usability. WAMMI is used by many researchers as an important tool for testing the usability of any website. It's a scientifically approved psychometric questionnaire. This questionnaire includes three sections. The first section contains the demographics of the respondents: gender, age, and employment status. The second section poses 20 standard questions to measure the five usability sub-scales (i.e. attractiveness, controllability, efficiency, helpfulness, and learnability). It provides a Global Usability Score (GUS) for the website. The final section consists of open-response questions to gather participants' opinions regarding the best features of the website, their main reasons for using the website, and the improvements needed for the website. The feedback from the respondents was stored in the WAMMI database. After the survey, WAMMI provided reports for each student and academic staff member, with a usability analysis based on the feedback they provided.

\subsection{Research Model}

This research followed the model used by Jabar et al. (2013). This model involves a dependent variable usability, as a dependent variable, and university website, as an independent variable, see Figure 1. In this model, the five factors of WAMMI used to assess the university website usability which in terns serve as guidelines.

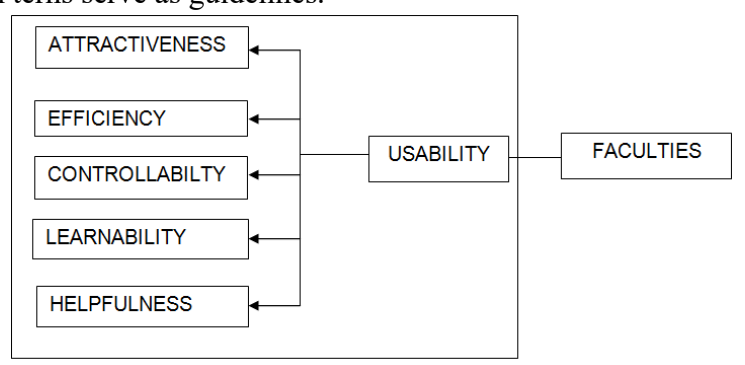

Figure 1. Usability Research Model (Jabar et al., 2013)

\subsection{Research Objectives}

The objective of this study is to test the University of Zakho website usability. This can be done by achieving the following sub-objectives:

- To analyse the website's usability on the scales of attractiveness, controllability, efficiency, helpfulness, learnability.
- To get participants' opinions regarding the best aspects of the website and whether they felt anything was missing from the website.

\subsection{Sample Selection}

Participants in this study included students and academic staff related to two faculties (the faculty of Science and the faculty of Humanities) at the University of Zakho. This study conducted during 6 months of the academic year (2017-2018). All students and academic staff were selected from these two faculties. There were 3,200 students and 354 academic staff. Cluster sampling was used to choose between faculties and their departments. The faculties in the University of Zakho were grouped into two clusters. First, the Faculty of Science was considered as cluster A and the Faculty of Humanities was considered as cluster B. Simple random sampling was applied to both clusters. At the University of Zakho there were 3,200 students and 354 academic staff, for a total of 3,554. The Slovin's formula was used in order to define a required size of respondents (Ariola, 2006). The following is the Slovin's formula with the sample size of this study.

$$
\begin{aligned}
n=N / & (1+N e 2) \\
\text { Where } n & =\text { number of respondents } \\
N & =\text { total population } \\
e & =\text { error tolerance } \\
n & =3554 /(1+3554(0.05) 2) \\
& =359.53 \\
& =360
\end{aligned}
$$

Allocated questionnaire of this study was distributed among 400 respondents, of which 311 were completed. An equal sample size (200) was assigned to each faculty to gain a credible number of responded questionnaires. In each faculty, the respondents were selected randomly.

\section{ANALYSIS AND RESULTS}

The data collected in this study were analysed in different ways to test the website usability. These were descriptive analysis, the students' WAMMI analysis, and the academic staff's WAMMI analysis. as well as discussion and recommendations. The Statistical Package for Social Sciences (SPSS) version 17 was used for the descriptive analysis. WAMMI reports were generated by the WAMMI website (http://www.wammi.com/).

\subsection{Descriptive Analysis}

Table 2 provides a descriptive analysis of the participants in the study.

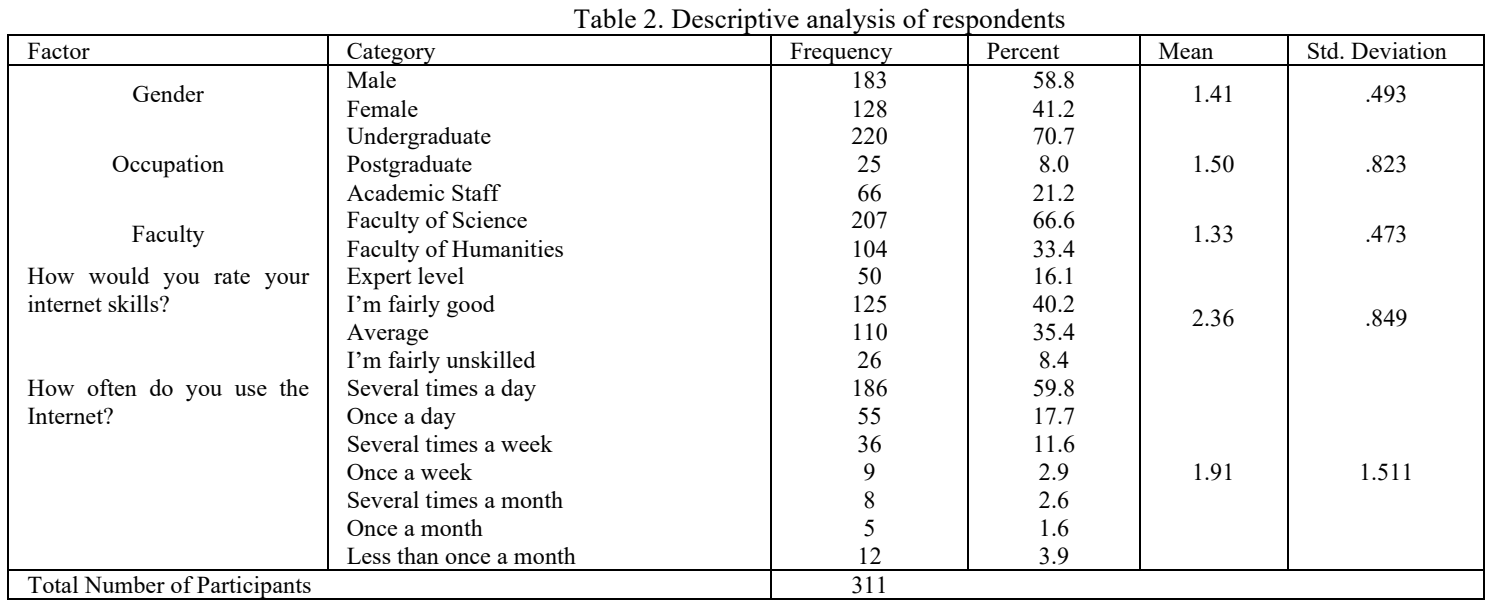


Of the 311 participants in the study, $58.8 \%$ were male and $41.2 \%$ were female, $78.7 \%$ were undergraduate and postgraduate students and $21.2 \%$ were academic staff from the two faculties in the University of Zakho. For internet skills, $56.3 \%$ of the respondents were fairly good or expert, while $35.4 \%$ and $8.4 \%$ were average or fairly unskilled, respectively. Of the respondents, $77.5 \%$ were using the internet at least once a day. The others were using the internet once or several times a week and a few of them were using the internet once or several times a month. This showed that most of the participants had internet skills and were using the internet frequently.

\subsection{WAMMI Analysis of Student Responses}

Students' WAMMI reports were generated by the WAMMI website. These reports showed the number of respondents to the fixed choice question in each category, such as gender, including those whose response could not be categorised. Each category of students was shown as percentages. In addition, these reports showed the average values that the University of Zakho site received for WAMMI five scales: attractiveness, controllability, efficiency, helpfulness, and learnability. the Global Usability Score (GUS) was a measured composite of statements from each scale and category. Finally, participants' opinions were obtained from open-response questions.

Table 3. The Global Usability Score (GUS) for each category of student

\begin{tabular}{|c|c|c|}
\hline Choice & Number of Respondents & $\begin{array}{c}\text { Global Usability Score } \\
\text { (GUS) }\end{array}$ \\
\hline \multicolumn{3}{|c|}{ Gender } \\
\hline Male & $132(53 \%)$ & 34.00 \\
female & $113(46 \%)$ & 34.08 \\
\hline \multicolumn{3}{|c|}{ Faculty } \\
\hline science & $168(68 \%)$ & 34.57 \\
humanities & $77(31 \%)$ & 32.88 \\
\hline
\end{tabular}

Table 3 displays responses number of each category to the fixed-choice question, including those whose response could not be categorised. Respondents of each category also is shown as percentage. The Global Usability Score (GUS) for each category is below $50 \%$. This means that all students rated the usability of the website low.

Table 4: WAMMI ratings by each category of student

\begin{tabular}{|c|c|c|c|c|c|}
\hline Choice & \multicolumn{5}{|c|}{ Mean rating for each of the WAMMI scales } \\
\hline & $\begin{array}{c}\text { Attracti } \\
\text { veness }\end{array}$ & $\begin{array}{c}\text { Control } \\
\text { lability }\end{array}$ & $\begin{array}{c}\text { Efficie } \\
\text { ncy }\end{array}$ & $\begin{array}{c}\text { Helpfuln } \\
\text { ess }\end{array}$ & $\begin{array}{c}\text { Learnabi } \\
\text { lity }\end{array}$ \\
\hline \multicolumn{6}{|c|}{ Gender } \\
\hline Male & 39.24 & 34.11 & 33.72 & 34.70 & 30.27 \\
Female & 36.64 & 35.30 & 32.84 & 37.05 & 30.47 \\
\hline \multicolumn{6}{|c|}{ Faculty } \\
Science & 37.51 & 36.01 & 35.59 & 34.84 & 30.75 \\
Humanities & 39.19 & 31.71 & 28.35 & 37.84 & 29.52 \\
\hline
\end{tabular}

Claridge and Kirakowski (2016) said that WAMMI scores are shown as percentiles, so a score of (50) represents the average score for each scale. Also, they mentioned that the higher than (50) is indicated more usable of the website and lower than (50) is indicated less usable of the website. Table 4 shows the WAMMI scales rating by students. These ratings range from a low of 28.35 to a high of 39.24 for the five WAMMI scales. This means that all five scales were less than 50, indicating that the usability of the University of Zakho website is low in the students' opinion.

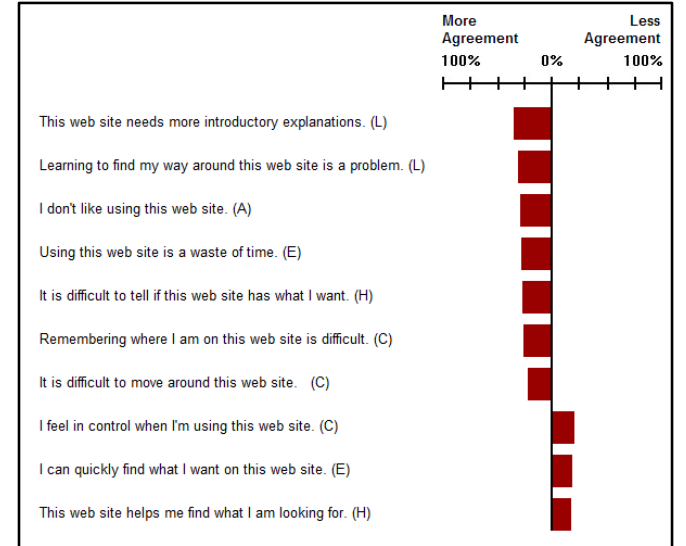

Figure 2. Ten most divergent items of the WAMMI statements

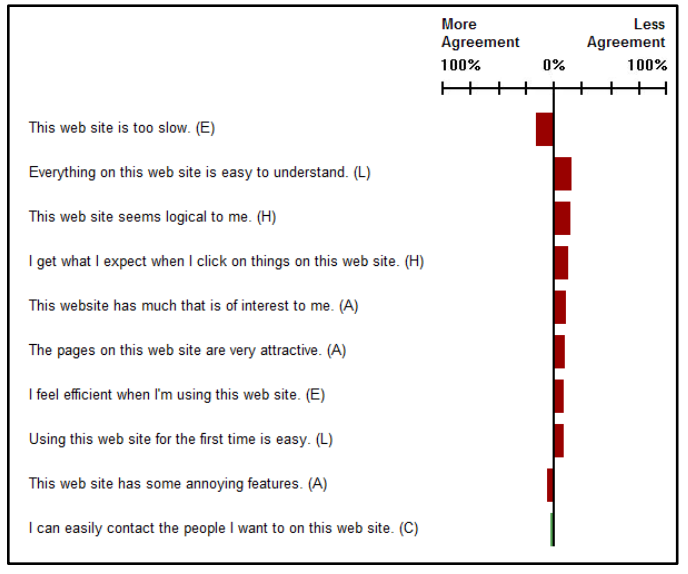

Figure 3. Ten least divergent items of the WAMMI statements

Figures 2 and 3 show the respondents' ratings on each of the WAMMI statements. In these two figures, green bars would indicate statements on which the site was rated more favourably. The red bars show those statements on which the site was rated less favourably. Also, the length of the bar shows how much respondents agreed or disagreed with the statement. The longer the bar, the greater the difference. For instance, $100 \%$ shows maximum agreement or disagreement with the statement. Further, if the bar to the right of the statement is green, that means the respondents are more in favour of the site. If it is red, that means the website may have a problem there. Based on that, the responses to the 20 standard questions of the WAMMI questionnaire showed that students rated the five usability sub-scales (i.e. Attractiveness, Controllability, Efficiency, Helpfulness and Learnability) low, as shown by the red bars.

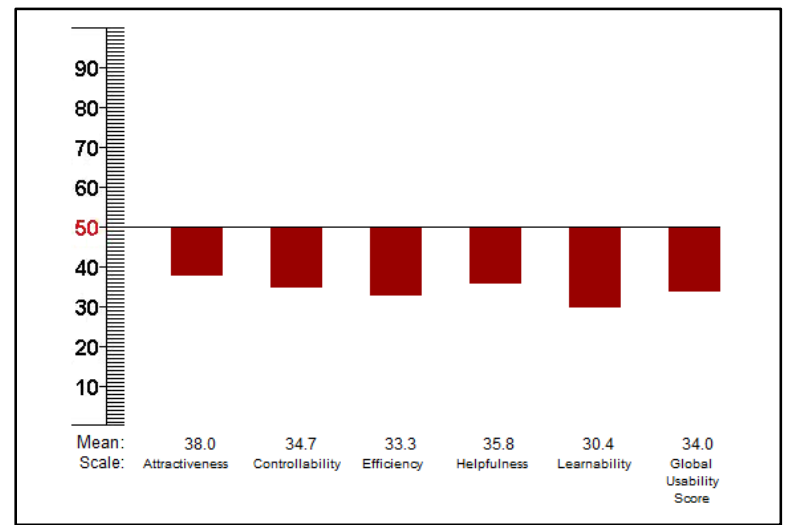

Figure 4. Average Values and Global Usability Score (GUS) for the WAMMI scales 
Figure 4 shows the GUS and the average values the site received. To explain, if the average value of each scale is above (50), it is shown as a green bar. if the average value of each scale is below (50), it is shown as a red bar. Based on the WAMMI report, if the scale measured below (30) or above (70) this shows that the site is exceptional on that scale. For the University of Zakho website, the bars extend downward from the '50' line but not as far as the ' 30 ' line. This means that the website needs more improvement in all five WAMMI scales for usability.

To get students' opinions about the best aspects of the website and whether they felt anything was missing, the open-response questions were analysed. The first question was 'What do you think is the best feature of this website, and why?'. Most of the students said that the best features of this website are news, events, and faculty departments' study programmes in three languages (English, Arabic and Kurdish) to distribute new information and activities among students quickly. For instance, one respondent said 'The best feature of this website is to have information related to any activity quickly'. Another said 'I can reach much information there related to us'. The second question was 'What were your main reasons for using this website?'. Most of the students indicated that using this website was important to have all related information about academic calendar, required credits for each study programme, course syllabi and electronic library to access all courses' resources. For instance, one respondent said 'Every time I need to have information related to my study programme and course resources...'. Another said 'It could help us to have important information'. The third question was 'What feature of this website do you think should be improved, and why?'. Unfortunately, most of the students said that this website needs to have accurate information related to us, to integrate student information and to change the structure of the website to navigate on the website easily. Also, it needs to speed up internet services on the university campus to have what they need quickly. Therefore, the navigation process and having important information from the website were weak and needed improvement to achieve a higher level of satisfaction in the students' opinion of the usability of the website.

\subsection{WAMMI Analysis of Academic Staff Responses}

Academic staff's WAMMI reports were generated by the WAMMI website. The respondents' number of each category to the fixed-choice question were shown, including those whose response could not be categorised. Respondents of each category also is shown as percentage. In addition, these reports showed the average values the University of Zakho site gets for the five WAMMI scales. The Global Usability Score (GUS) was a measured composite of statements from each scale and category. Finally, the staff members' subjective opinion was obtained from the open-response questions.

Table 5. The Global Usability Score (GUS) for each category of

\begin{tabular}{|c|c|c|}
\hline \multicolumn{3}{|c|}{ academic staff } \\
\hline Choice & $\begin{array}{c}\text { Number of } \\
\text { Respondents }\end{array}$ & $\begin{array}{c}\text { Global Usability Score } \\
\text { (GUS) }\end{array}$ \\
\hline \multicolumn{3}{|c|}{ Gender } \\
\hline Male & $49(74 \%)$ & 34.94 \\
Female & $17(25 \%)$ & 31.00 \\
\hline \multicolumn{3}{|c|}{ Faculty } \\
\hline Science & $39(59 \%)$ & 36.08 \\
Humanities & $27(40 \%)$ & 30.81 \\
\hline
\end{tabular}

Table 5 displays the number of academic staff in each category of response to the fixed-choice questions, including those whose response could not be categorised. Respondents of each category also is shown as percentage. The Global Usability
Score (GUS) for each category is below $50 \%$. This means that academic staff rated the usable of the website low.

Table 6. WAMMI ratings by each category of academic staff

\begin{tabular}{|c|c|c|c|c|c|}
\hline Choice & \multicolumn{5}{|c|}{ Mean rating for each of the WAMMI scales } \\
\hline & $\begin{array}{c}\text { Attracti } \\
\text { veness }\end{array}$ & $\begin{array}{c}\text { Controll } \\
\text { ability }\end{array}$ & $\begin{array}{c}\text { Efficie } \\
\text { ncy }\end{array}$ & $\begin{array}{c}\text { Helpfuln } \\
\text { ess }\end{array}$ & $\begin{array}{c}\text { Learnabi } \\
\text { lity }\end{array}$ \\
\hline \multicolumn{6}{|c|}{ Gender } \\
\hline Male & 36.86 & 39.92 & 33.14 & 34.88 & 32.22 \\
Female & 37.65 & 25.12 & 32.71 & 30.76 & 30.29 \\
\hline \multicolumn{7}{|c|}{ Faculty } \\
\hline Science & 39.10 & 38.77 & 36.08 & 36.87 & 31.97 \\
Humanities & 34.11 & 32.26 & 28.63 & 29.41 & 31.37 \\
\hline
\end{tabular}

Table 6 shows the WAMMI ratings by academic staff. These ratings range from a low of 25.12 to a high of 39.92 for the five WAMMI scales. This means that all five scales were less than 50. This shows that the usability of the University of Zakho website is low in the opinion of the academic staff.

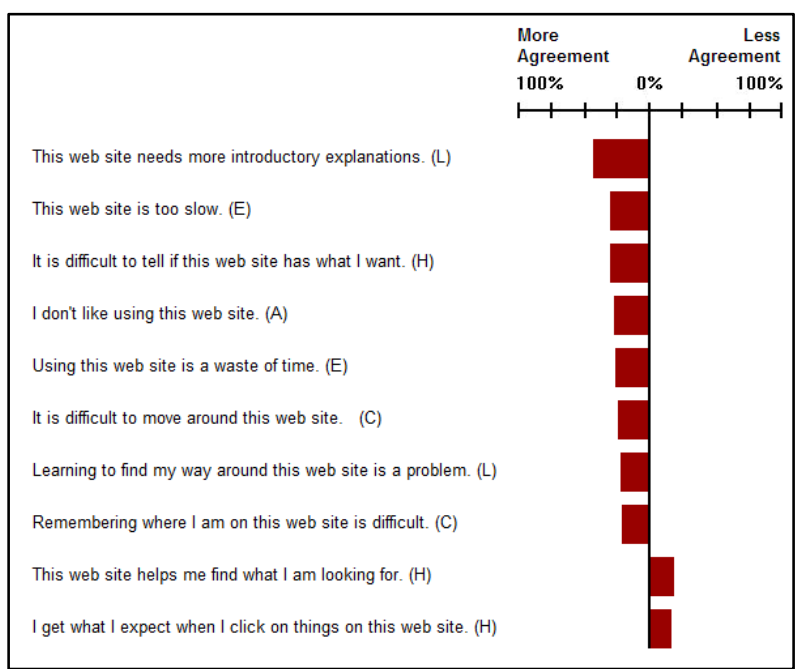

Figure 5. Ten most divergent items of the WAMMI statements

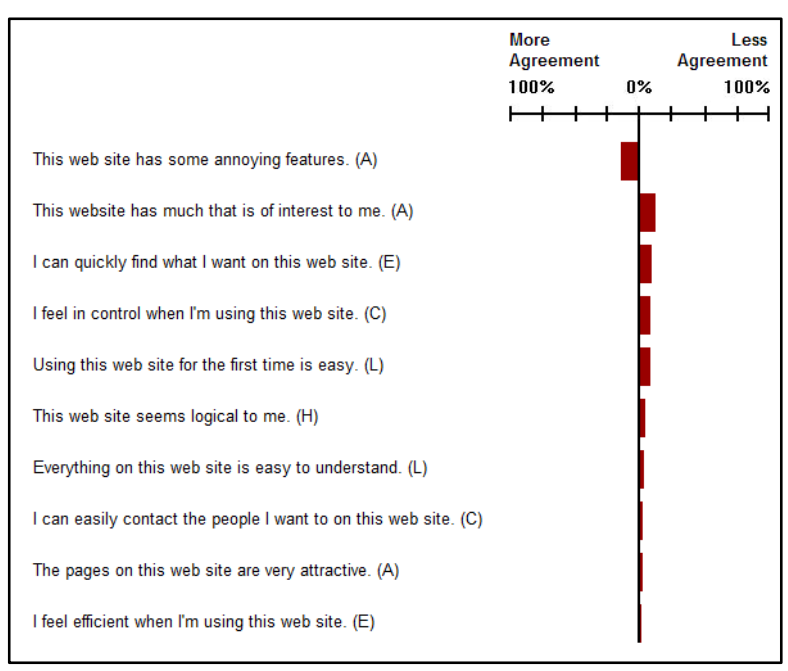

Figure 6. Ten least divergent items of the WAMMI statements

Figures 5 and 6 show the ratings by academic staff on each of the WAMMI statements. In these two figures, the green bars show those statements on which the site was rated more favourable. The red bars show those statements on which the site was rated less favourable. Also, the length of the bar shows how much respondents agreed or disagreed with the statement. The longer the bar, the greater the difference. For instance, $100 \%$ shows maximum agreement or disagreement with the statement. Further, if the bar to the right of the statement is green, that means the respondents are more in favour of the site. 
If it is red, that means the website may have a problem there. Based on that, the responses to the 20 standard questions of the WAMMI questionnaire showed that academic staff rated the five usability sub-scales (i.e. Attractiveness, Controllability, Efficiency, Helpfulness and Learnability) low, as shown by the red bars.

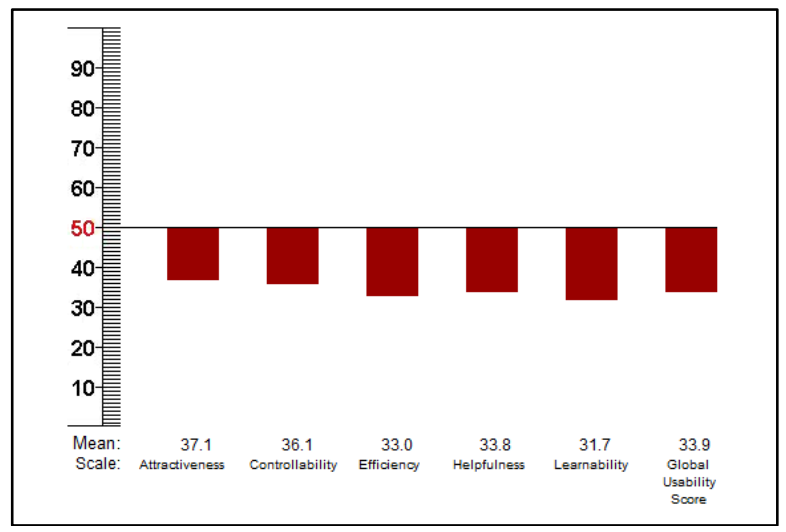

Figure 7. Average Values and Global Usability Score (GUS) for the WAMMI scales

Figure 7 shows the average values and GUS of WAMMI five scales. The GUS is measured composite of statements from each scale. For explanation, if the average value of each scale is above (50), it is shown as a green bar. if the average value of each scale is below (50), it is shown as a red bar. Based on the WAMMI report, if the scale measured below (30) or above (70) this shows that the site is exceptional on that scale. For the University of Zakho website, the bars extend downward from the ' 50 ' line but not as far as the ' 30 ' line. This means that the website needs more improvement in all five WAMMI scales for usability.

To get the academic staff's subjective opinion regarding the best aspects of the website and whether they felt anything was missing from the website, three questions were asked: 'What do you think is the best feature of this website, and why?', 'What were your main reasons for using this website?' and 'What feature of this website do you think should be improved, and why?'. Most of the academic staff said that the best features of this website were that it was easy to navigate to get up-todate information about the university's news and events, that it was available in three languages (English, Arabic and Kurdish), and that it had clear and extensive information about all activities. For example, one respondent said, 'This site is well developed and easy to use and navigate as well as it is available in three languages...'. Another said, 'It is easy to use and clear for searching and it is not complex...'. However, some academic staff members said that the website needs updating in daily information and it should have more pages with information related to undergraduate and postgraduate students regarding the study programmes and their activities. Also, this website was still complex from the viewpoint of some academic staff.

\section{DISCUSSION AND RECOMMENDATIONS}

This study revealed that the five WAMMI scales (attractiveness, controllability, efficiency, helpfulness, and learnability) are important to determine the usability of the university website. However, these five scales were rated lower on the usability of the University of Zakho website in the views of both students and academic staff.

The Global Usability Scale (GUS) of the Attractiveness category was weighted low by students (38.0) and academic staff (37.1). Also, the GUS for the Controllability category was weighted low by students (34.7) and academic staff (36.1). The GUS of the Efficiency category also was weighted low by students (33.3) and academic staff (33.0). The GUS of the Helpfulness and Learnability categories were weighted low by students (35.8), (30.4) and academic staff (33.8), (31.7), respectively. The overall GUS for the website of the University of Zakho was (34.0) from students and (33.9) from academic staff, which are described as low on the usability scale. This is because the website needs more improvement in the structure, providing more student information and up-to-date information related to university activities based on the viewpoint of students and academic staff. This also showed that all five WAMMI scale categories need to be improved to give users more satisfaction when using the university website.

The recommendation from this study is to consider all the standard statements of the five WAMMI scale categories during the design and updating of the website of any university (see Table 7). Therefore, the website designers of the university should follow the aforementioned recommendation to improve the attractiveness and functionality of the university website. Also, they should involve students and academic staff in to the process of developing the university website based on their opinion. Also, they have to be a part of testing process. This can lead to more user satisfaction from using the website.

Table 7: The standard statements of the five WAMMI scales

\begin{tabular}{|c|c|}
\hline $\begin{array}{l}\text { WAMMI Scale } \\
\text { Category }\end{array}$ & The Standard Statements \\
\hline Attractiveness & $\begin{array}{l}\text { - } \begin{array}{l}\text { I don't like using this website. } \\
\text { - }\end{array} \text { This website has much that is of } \\
\text { interest to me. } \\
\text { - The pages on this website are very } \\
\text { attractive. } \\
\text { - This website has some annoying } \\
\text { features. }\end{array}$ \\
\hline Controllability & 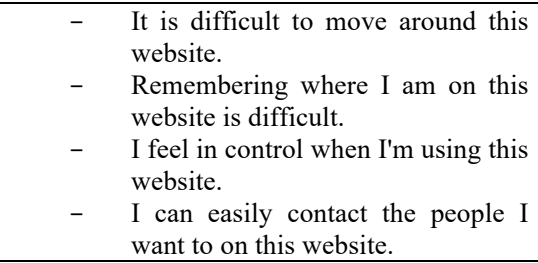 \\
\hline Efficiency & $\begin{array}{ll}- & \text { This website is too slow. } \\
\text { - } & \text { Using this website is a waste of } \\
\text { time. } \\
\text { - I can quickly find what I want on } \\
\text { this website. } \\
\text { - I feel efficient when I'm using this } \\
\text { website. }\end{array}$ \\
\hline Helpfulness & $\begin{array}{ll}- & \text { This website seems logical to me. } \\
\text { - } & \text { This website helps me find what I } \\
\text { am looking for. } \\
\text { - } \quad \text { It is difficult to tell if this website } \\
\text { has what I want. } \\
\text { - I get what I expect when I click on } \\
\text { things on this website. }\end{array}$ \\
\hline Learnability & 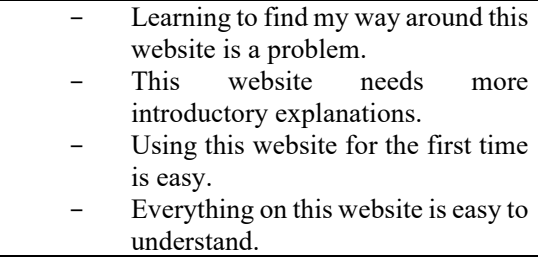 \\
\hline
\end{tabular}

\section{CONCLUSIONS AND FUTURE WORK}

This research contributes empirical evidence for educational institutes regarding the importance of features to consider during the development steps and testing the usability of an educational website. This study aimed to test the usability of the University of Zakho based on the WAMMI five factors. 
The WAMMI questionnaire is an important tool to test any website's usability from the perspective of the users. However, such tool is not appropriate for testing websites from the perspective of developers. Therefore, this study showed that the overall scores on the five WAMMI scales were low from the viewpoint of both students and academic staff. These five scales are attractiveness, controllability, helpfulness, efficiency, and learnability.

Based on that, the usability scales of WAMMI can serve as guidelines for developers and web designers in building a well satisfy website by users. Therefore, any university should involve primary users, such as students and academic staff, during the website development process. This can be helpful in having a satisfy website based on the opinions of students and academic staff during the development and testing process.

This researcher will conduct the same study on all groups of users, starting with visiting researchers, guests, and alumni. The evaluator-based methods will be used to evaluate the website from the perspective of developers, and tool-based methods will be used to identify usability problems of the website.

\section{ACKNOWLEDGEMENTS}

We would like to thank students and academic staff of both faculties of Science and Humanities of the University of Zakho for their participation and support. Also, I would like to thank Dr Jurek Kirakowski, Director of Human Factors Research Group, University College Cork, Ireland, for granting us permission to use WAMMI free of charge for testing the usability of the website of the University of Zakho.

\section{REFERENCES}

Abdullah, R., \& Wei, K. T. (2008). Usability measurement of Malaysia online news websites. International Journal of Computer Science and Network Security, 8(5), 159-165.

Ahmad, A., Hussain, A., Flayyih, O. H., Abdulwahab, W., \& Sabri, M I. (2017). Utilizing WAMMI Components to Evaluate the Usability of E-commerce Website. Journal of Telecommunication, Electronic and Computer Engineering (JTEC), 9(2-11), 139-143.

Ahmed, N. S. (2013). A fractal-based model to improve cooperation among physicians in distributed healthcare information systems. University of Malaya.

Al-Radaideh, Q. A., Abu-Shanab, E., Hamam, S., \& Abu-Salem, H. (2011). Usability Evaluation of Online News Websites: A User Perspective Approach. International Journal of Human and Social Sciences, 6(2), 114-122.

Ariola, M. M. (2006). Principles and methods of research: Rex Book Store.

Bautista, J. (2010). Students' perspectives on university Web site usability: An evaluation: Pepperdine University.

Caglar, E., \& Mentes, S. A. (2012). The usability of university websites-a study on European University of Lefke.
International Journal of Business Information Systems, 11(1), 22-40.

Claridge, N., \& Kirakowski, J. (2016). WAMMI Website. Retrieved October 12, 2018, from http://www.wammi.com/index.html

Haji, V. M., \& Ahmed, N. S. (2017). A web-based management information system for Human resources in selected universities of Duhok Province. Science Journal of University of Zakho, 5(2), 214-220.

Harpel-Burk, P. (2006). Medium-sized universities connect to their libraries: Links on university home pages and user group pages. Information technology and libraries, 25(1), 12-23.

Hasan, L. (2012). Investigating the relative importance of design criteria in the evaluation of the usability of educational websites from the viewpoint of students. Paper presented at the Proceedings of the World Congress on Engineering (WCE 2012).

Hasan, L. (2014). Evaluating the usability of educational websites based on students' preferences of design characteristics. International Arab Journal of e-Technology, 3(3), 179-193.

Huang, L.-M., \& Bilal, D. (2019). Usability of University Recruitment Web Pages from International Doctoral Students' Perspectives. Paper presented at the International Conference on Human-Computer Interaction.

Jabar, M., Usman, A., \& Awal, A. (2013). Assessing the usability of university websites from users' perspective. Australian Journal of Basic and Applied Sciences, 7(10), 98-111.

Kaya, A., Ozturk, R., \& Gumussoy, C. A. (2019). Usability Measurement of Mobile Applications with System Usability Scale (SUS) Industrial Engineering in the Big Data Era (pp. 389-400): Springer.

Melgarejo, L. T., Del Río, C. Z., \& Vilchez, E. Q. (2019). Exploring the Relationship Between Web Presence and Web Usability in Peruvian Universities. Paper presented at the International Conference on Human-Computer Interaction.

Mentes, S. A., \& Turan, A. H. (2012). Assessing the usability of university websites: An empirical study on Namik Kemal University. Turkish Online Journal of Educational Technology-TOJET, 11(3), 61-69.

Mustafa, S. H., \& A1-Zoua'bi, L. F. (2008). Usability of the academic websites of Jordan's universities an evaluation study. Paper presented at the Proceedings of the 9th International Arab Conference for Information Technology.

Panagopoulos, C., Menychtas, A., Tsanakas, P., \& Maglogiannis, I. (2019). Increasing Usability of Homecare Applications for Older Adults: A Case Study. Designs, 3(2), 23.

Patterson, K., \& Alles, A. (2004). Usability and meeting the needs of educational Web site users. Paper presented at the Proceedings of the Tenth Australian World Wide Web Conference.

Thowfeek, M. H., \& Salam, M. N. A. (2014). Students' assessment on the usability of E-leaming websites. Procedia-Social and Behavioral Sciences, 141, 916-922.

Yan, P., \& Guo, J. (2010). The research of web usability design. Paper presented at the 2010 The 2nd International Conference on Computer and Automation Engineering (ICCAE). 